\title{
Linking nursery nutritional status and water availability post-planting under intense summer drought: the case of a South American Mediterranean tree species
}

\author{
Juan F Ovalle ${ }^{(1)}$, Eduardo C \\ Arellano ${ }^{(1-2)}$, Juan A Oliet ${ }^{(3)}$, \\ Pablo Becerra ${ }^{(1-2)}$, Rosanna \\ Ginocchio ${ }^{(1-2)}$
}

\begin{abstract}
Drought-avoidance traits of South American Mediterranean tree species are crucial attributes to be considered in nursery practices aimed at improving the performance of seedlings exposed to intense summer drought in dryland reforestation projects. In this study, we determined the relation between nursery fertilization doses and the development of drought-avoidance traits of the soapbark tree Quillaja saponaria (Mol.) under contrasting watering regimes following post-planting. Seedlings were grown for 6 months using four increasing doses of controlled-release fertilizer $\left(0,3,6\right.$, and $12 \mathrm{~g} \mathrm{~L}^{-1}$ of Basacote ${ }^{\circledR}$ Plus $15: 8: 12)$. After outplanting, half of the seedlings were watered weekly and the other half were left unwatered for one growing season from September 2011 to May 2012. Seedlings were periodically measured for morphological and ecophysiological parameters, and carefully harvested for root measurements at the end of the study. Our results showed that high fertilization doses produced significantly larger seedlings in the nursery with high nitrogen and phosphorous foliar concentrations, which resulted in a significantly higher shoot dry mass after outplanting. Unfertilized seedlings grown with water application had a significantly higher stem diameter, root dry mass and lower shoot/root compared with seedlings with high fertilizer dose. These results highlight the ability of this species to maintain drought-avoidance traits, such as high xylem water potential and chlorophyll fluorescence, during the first 3 months of the 7-month drought period. High nutrient loading, although resulting in improved shoot productivity after outplanting, did not make a significant contribution to the early development of drought-avoidance traits in $Q$. saponaria.
\end{abstract}

Keywords: Dryland Forest Restoration, Plant Quality, Root Architecture, Seedling Fertilization, Water-stress Resistance

\section{Introduction}

The Mediterranean ecosystems are char acterized by strong seasonality with high temperatures and low or no precipitation during the summer months; thus, soil water availability is a major limiting factor for the tree seedling survival and growth (Peñuelas 2001, Pardos et al. 2014). In
South American Mediterranean ecosystems, the reforestation success is limited by both low water availability and poor nursery management and planting techniques, especially in highly degraded sites (Becerra et al. 2011). In this area, tree seedling mortality can be close to $70 \%$ after first post-planting growing season (Becerra
(1) Center of Applied Ecology \& Sustainability (CAPES), Pontificia Universidad Católica de Chile, Avenida Libertador Bernardo O'Higgins 340, 8320000 Santiago (Chile); (2) Departamento de Ecosistemas y Medio Ambiente, Facultad de Agronomía e Ingeniería Forestal, Pontificia Universidad Católica de Chile, Avenida Vicuña Mackenna 4860, 8320000 Santiago (Chile) (3) Department of Natural Systems and Resources, Universidad Politécnica de Madrid, Ciudad Universitaria s/n, 28040 Madrid (Spain)

@ Eduardo C Arellano (earellan@uc.cl)

Received: Oct 27, 2015 - Accepted: Jan 22, 2016

Citation: Ovalle JF, Arellano EC, Oliet JA, Becerra P, Ginocchio R (2016). Linking nursery nutritional status and water availability post-planting under intense summer drought: the case of a South American Mediterranean tree species. iForest 9: 758-765. - doi: 10.3832/ifor1905-009 [online 2016-06-03]

Communicated by: Claudia Cocozza et al. 2011, Benigno et al. 2014). Additionally, the sustainability of reforestation projects is threatened by climate change projections that indicate an increase in drought severity; therefore, plant production and reforestation techniques will need to be adapted to soil water limitations (Vallejo et al. 2012).

To adapt to water stress conditions and avoid early mortality, plants have evolved different structural and functional traits, such as deep roots, higher root length density, a reduced shoot:root balance, stomatal conductance, and/or osmotic adjustment (Lo Gullo \& Salleo 1988, Valladares \& Sánchez-Gómez 2006, Padilla et al. 2015). It has been reported that these adaptive traits could be considered in nursery or reforestation practices in areas with Mediterranean-type climate (Vilagrosa et al. 2003, Ovalle et al. 2015). In this context, early nutrient loading is suggested to increase drought resistance of seedlings, which help to maintain a positive water balance during initial field establishment (Luis et al. 2009, Cuesta et al. 2010, Villar-Salvador et al. 2012). Seedlings that received high levels of fertilizer increased their root growth, lead- 
ing to an improved water potential and, consequently, to improved survival rates during the drought season following outplanting (Oliet et al. 2009).

Seedlings with an excessive nutrient load and large size do not always respond well after outplanting in Mediterranean systems (Luis et al. 2009). The effect of the fertilization is dependent on the drought intensity during the establishment stage (Cortina et al. 2013). Indeed, the positive relation between plant nutrition and growth could be negatively affected in regions with severe drought periods lasting five or more months (Tan \& Hogan 1997). Under this scenario, seedling quality will be associated with the development of phenotypes with drought-avoidance traits, such as low leaf area, high root collar diameter, low shoot:root ratio, low shoot height, and large root volume (Trubat et al. 2006). Previous studies carried out in xeric Mediterranean conditions concluded that limited nitrogen $(\mathrm{N})$ application decreased the leaf area, thereby improving seedling resistance to drought after outplanting (Tan \& Hogan 1997, Trubat et al. 2008). By contrast, high seedling $\mathrm{N}$ loading in the nursery produced a morphological imbalance by increasing shoot biomass over root biomass following planting (Trubat et al. 2008, Cortina et al. 2013). Under dry conditions, this morphological imbalance increases transpiration rates and reduces stem water potential, root hydraulic conductivity (Hernández et al. 2009), and stomatal conductance (Jacobs et al. 2004). Low shoot:root ratios could promote a more conservative water use and improve the likelihood of survival after outplanting (Leiva \& Fernández-Alés 1998, Lloret et al. 1999). Furthermore, seedlings ability to generate new roots immediately after planting generates a rapid soil colonization and field rooting (Villar-Salvador et al. 2012). In terms of nutrients uptake and their effects on root development, Trubat et al. (2012) found a positive effect of low $\mathrm{N}$ and phosphorous $(P)$ on increases in specific root length.

Despite the positive effect of nursery nutrient loading on the physiological responses of seedlings, there is little information about the influence of nursery fertilization on the development of morphological traits under different drought levels. We hypothesized that the positive effect of high nursery nutrient loading on the development of drought-avoidance traits is conditioned by the availability of soil water in the field. Thus, the objective of our study was to assess the role of nursery fertilization on the short-term development of drought-avoidance traits of a South American Mediterranean species growing under contrasting field water regimes. The study was conducted using the soapbark tree Quillaja saponaria Mol. (Quillajaceae) which is a representative evergreen tree species of South American Mediterranean forests $\left(30^{\circ} \mathrm{S}, 38^{\circ} \mathrm{W}-\right.$ Donoso 1982$)$, and it is the most common tree species used for the reforestation of the highly degraded forests (Becerra et al. 2013). In addition, this species has the ability to develop a strong taproot as one of the main survival strategies to extend drought periods (Ovalle et al. 2015).

\section{Material and methods}

Nursery treatments and measurements

Seeds of $Q$. saponaria were collected from a forest located in Cuesta Zapata $\left(33^{\circ}\right.$ $23^{\prime} \mathrm{S}, 71^{\circ} 16^{\prime} \mathrm{W}$ ), central Chile. Seeds germination and initial growth took place in the Pumahuida Ltda. Nursery (Santiago, Chile). Seedlings were grown for 8 months in individual $200 \mathrm{~cm}^{3}$ pots filled with peat and were sprayed twice daily with water mist, following seedling production protocols in Chilean nurseries (González et al. 2011). The seedlings selected for the study $(n=240)$ were homogeneous in size $(6-8 \mathrm{~cm}$ in height, 1-1.5 $\mathrm{mm}$ in stem diameter).

Seedlings were transplanted to $400 \mathrm{~cm}^{3}$ black polyethylene bags at a research site of the Pontificia Universidad Católica of Chile ( $33^{\circ} 29^{\prime} \mathrm{S}, 70^{\circ} 36^{\prime} \mathrm{W}$ ). The potting substrate comprised a mixture of loam soil, sandy soil, and compost at a ratio of 2:1:1 prepared in the nursery. The chemical characteristics of the substrate were as follows: organic matter content (WalkleyBlack method) 13.90\%; pH (soil:water, 1:2.5) 7.00; electric conductivity (EC) $1.50 \mathrm{dS} \mathrm{m}^{-1}$; $\mathrm{N}$ concentration (Kjeldahl digestion procedure) $4.7 \mathrm{~g} \mathrm{~kg}^{-1}$; P (Olsen method - Olsen \& Sommers 1982) $4.1 \mathrm{~g} \mathrm{~kg}^{-1}$; exchangeable $\mathrm{K}$ (ammonium acetate method) $4.6 \mathrm{~g} \mathrm{~kg}^{-1}$; medium levels of $\mathrm{Na}^{+}, \mathrm{Ca}^{2+}, \mathrm{Mg}^{2+}$, and $\mathrm{K}^{+}$ were determined by wet-ashing techniques and analyzed using an ion chromatograph (Sparks 1996). Seedlings were grown under semi-controlled conditions covered with a $50 \%$ Rashell mesh to avoid excess radiation for 6 months starting from January 2011. All the seedlings were watered three times a week with $0.15 \mathrm{~L} \mathrm{plant}^{-1}$. At the end of nursery period, seedlings were moved to an open area and watering was reduced to half to prepare them to final transportation to the field site.

In January 2011, the nursery treatments were established as a completely randomized design with four fertilization treatments. Each treatment was applied to 60 replicates (240 plants in total). The experimental unit and the sampling unit was an individual plant. To enable comparisons, the fertilizer treatments comprised incremental doses of $\mathrm{N}$ units of $0.00,0.45,0.90$, and $1.80 \mathrm{~g} \mathrm{~N} \mathrm{~L}^{-1}$, equivalent to 0 (unfertilized or OF), 3 (low dose: 3F), 6 (medium dose: 6F), and $12 \mathrm{~g} \mathrm{~L}^{-1}$ (high dose: $12 \mathrm{~F}$ ) of a controlled-release fertilizer (CRF), respectively. Basacote ${ }^{\oplus}$ Plus (COMPO, Germany) 15:8:12 (80 g kg-1 $\mathrm{NH}_{4}^{+} ; 70 \mathrm{~g} \mathrm{~kg}^{-1} \mathrm{NO}_{3}^{-} ; 80 \mathrm{~g}$ $\mathrm{kg}^{-1} \mathrm{P}_{2} \mathrm{O}_{5} ; 120 \mathrm{~g} \mathrm{~kg}^{-1} \mathrm{~K}_{2} \mathrm{O} ; 20 \mathrm{~g} \mathrm{~kg}^{-1} \mathrm{MgO} ; 50 \mathrm{~g}$ $\mathrm{kg}^{-1} \mathrm{SO}_{2} ; 0.4 \mathrm{~g} \mathrm{~kg}^{-1} \mathrm{Fe} ; 0.5 \mathrm{~g} \mathrm{~kg}^{-1} \mathrm{Cu} ; 0.6 \mathrm{~g} \mathrm{~kg}^{-1}$ $\mathrm{Mn} ; 0.2 \mathrm{~g} \mathrm{~kg}^{-1} \mathrm{Zn}$; $0.2 \mathrm{~g} \mathrm{~kg}^{-1} \mathrm{~B}$; $0.15 \mathrm{~g} \mathrm{~kg}^{-1} \mathrm{Mo}$ ) was used with a release period of 12 months (estimated for a constant temperature of $21^{\circ} \mathrm{C}$ ). This fertilizer has been commonly used in forest nurseries to extend the nutritional contribution to the field phase (Haase et al. 2006).

Upon completion of the nursery phase (June 2011) and before field plantation, a random sample $(n=15)$ of seedlings from each treatment was analyzed to estimate the effect of fertilization doses on shoot height $\left(\mathrm{S}_{\mathrm{H}}, \mathrm{cm}\right)$, stem diameter $\left(\mathrm{S}_{\mathrm{D}}, \mathrm{mm}\right)$, slenderness index $\left(\mathrm{S}_{1}, \mathrm{~cm} \mathrm{~mm}^{-1}\right)$, shoot dry mass $\left(S_{D M}, g\right)$, shoot:root ratio $\left(\mathrm{g} \mathrm{g}^{-1}\right)$, total root length (total $R_{L}, m$ ), total root volume (total $\left.R_{v}, \mathrm{~cm}^{3}\right)$, and root dry mass $\left(R_{D M}, g\right.$ $\left.\mathrm{g}^{-1}\right)$. Roots were separated from dry soil and the remaining soil particles separated by applying water at low pressure, taking care to collect all the fine roots that could be disconnected from the root plug. Shoots were cut at the cotyledon scar. Root morphological variables were quantified using a high-resolution scanner (1200 DPI resolution, Epson Perfection 4490 Scanner ${ }^{\circledast}$, Nagano, Japan) and image analysis software (WinRHIZO ${ }^{\oplus}$, Regent Instruments Inc., Quebec, Canada). $\mathrm{S}_{D M}$ and $\mathrm{R}_{\mathrm{DM}}$ were obtained by forced-air oven drying at $65^{\circ} \mathrm{C}$ until a constant weight was obtained. The shoot:root ratio was estimated as the quotient between $S_{D M}$ and $R_{D M}$. The slenderness $\left(S_{1}, \mathrm{~cm} \mathrm{~mm}^{-1}\right)$ was obtained from the quotient of $S_{H}$ and $S_{D}$. Foliar concentrations $\left(\mathrm{g} \mathrm{kg}^{-1}\right)$ of $\mathrm{N}, \mathrm{P}, \mathrm{K}, \mathrm{Ca}$, and $\mathrm{Mg}$ were determined by the laboratory of the Pontificia Universidad Católica of Chile from a composite leaf sample of three seedlings per treatment that were dried in an oven at $65^{\circ} \mathrm{C}$ for $48 \mathrm{~h}$. $\mathrm{N}$ concentration was determined using a LECO CNS-2000 Macro Elemental Analyzer ${ }^{\otimes}$ (Leco, Michigan, USA). $\mathrm{P}, \mathrm{K}, \mathrm{Ca}$, and $\mathrm{Mg}$ concentrations were determined using wet ash extraction and perchloric acid extracts in an auto-analyzer by gas-segmented continuous flow coupled to a flame photometer (Sparks 1996).

\section{Field treatments and measurements}

Seedlings were planted in "Quebrada de la Plata” ( $33^{\circ} 29^{\prime} \mathrm{S}, 70^{\circ} 52^{\prime} \mathrm{O}$; altitude 490 $\mathrm{m})$, located in central Chile. The study site is located in a recently abandoned flat grazing area, near to piedmont. The summer drought lasted 7 months during this study period, with maximum mean temperatures of $30^{\circ} \mathrm{C}$ and an absolute lack of rain for 5 months (Fig. 1). Soil is deep and has a colluvial origin, with clay loam textures and abundant gravel. Three composite soil samples (15 sub-samples) were taken from topsoil $(0-20 \mathrm{~cm})$ for determine the nutritional status and main chemical and physical properties of the soil in the study area. The results of the analysis in the laboratory indicated a total of $0.044 \mathrm{~g} \mathrm{~kg}^{-1} \mathrm{~N}, 0.031 \mathrm{~g}$ $\mathrm{kg}^{-1} \mathrm{P}_{2} \mathrm{O}_{5}, 0.334 \mathrm{~g} \mathrm{~kg}^{-1} \mathrm{~K}_{2} \mathrm{O}$, 6.0 soil pH $\left(\mathrm{H}_{2} \mathrm{O}\right)$, $0.2 \mathrm{dS} \mathrm{m}^{-1} \mathrm{EC}$, and $3.1 \%$ total organic matter. Seedlings were outplanted during the winter in 2011. The study area was fenced using a protection mesh $1.50 \mathrm{~m}$ high to prevent large animal herbivory (Morales et al. 
2015). Manually opened planting holes ( $0.40 \mathrm{~m}$ wide $\times 0.60 \mathrm{~m}$ deep) were distributed $1.5 \times 2.0 \mathrm{~m}$ apart to prevent interspecific competition for soil water. To avoid transplant shock, seedlings received $2 \mathrm{~L}$ of water every 2 weeks for 6 weeks until the beginning of the growing season, with warmer temperatures and no rain until September 2011.

Watering treatments were established in mid-September 2011. The field experimental design was a $4 \times 2$ factorial (four levels of nursery fertilization and two levels of field water regimes). Half of the seedlings of each of the four fertilization treatments ( 0 , 3,6 , and $\left.12 \mathrm{~g} \mathrm{~L}^{-1}\right)$ continued to receive weekly $2 \mathrm{~L} \mathrm{plant}^{-1}(\mathrm{~W}+)$ and half were left unwatered $(\mathrm{W}-)$. These watering regimes corresponded to moderate and severe water stress, respectively, based on the criterion commonly used in reforestation operations of semiarid environments (Luna 2006, Valenzuela 2007). Precipitation was negligible because of the severe drought during the study period (Fig. 1). Each treatment had 15 replicates ( 120 plants in total) randomly assigned to each planting spot. The experimental unit and sampling unit were an individual plant. The study site conditions were homogeneous in luminosity, temperature, and airflow, which allowed random assignment without blocking for external factors.

$\mathrm{S}_{\mathrm{H}}, \mathrm{S}_{\mathrm{D}}$, and survival were evaluated monthly. Pre-dawn xylem water potential $\left(\Psi_{\mathrm{w}}\right)$, chlorophyll fluorescence $\left(\mathrm{F}_{\mathrm{v}} / \mathrm{F}_{\mathrm{m}}\right)$, and stomatal conductance $\left(g_{s}, \mathrm{mmol} \mathrm{m}^{-2} \mathrm{~s}^{-1}\right)$ were assessed every 2 months between July 2011 and May 2012. For pre-dawn $\Psi_{w}$, five seedlings per treatment were randomly selected. Each sample was obtained from the terminal parts of lignified twigs 5 $\mathrm{cm}$ long with three or four mature leaves (second growing season). Measurements were carried out during predawn hours (04:00-07:00) using a Scholander pressure pump (Model $1000^{\circledR}$, PMS Instruments Inc., Corvallis, OR, USA). Midday measurements (11:00-13:00) were discarded because the pressure values reached at peak temperature exceeded the safety limit of the instrument $\left(\max \Psi_{\mathrm{w}}=-7.00 \mathrm{MPa}\right)$. Chlorophyll fluorescence, expressed as maximum photochemical efficiency (Fv/Fm), was measured on 12 randomly selected seedlings at peak radiation (12:00-14:00) using a portable modulated Chlorophyll Fluorometer (Model OS-30 ${ }^{\circledast}$, Opti-Sciences Inc., Hudson, $\mathrm{NH}$, USA) following the protocols described by Maxwell \& Johnson (2000). Each recorded value was a composite of measurements from three different leaves (mature leaves exposed to direct radiation) from the same plant. To obtain $g_{s}$ values ( $n$ = 5), an infrared gas analyzer (IRGA) Model $\mathrm{Cl}-340^{\oplus}$ (CID Inc., Camas, WA, USA) was used; the measurement was performed using the same sampling protocol described for $F_{v} / F_{m}$. We chose sampling days with similar temperatures and humidity for measurement of $\mathrm{g}_{\mathrm{s}}$ to diminish the variabil-

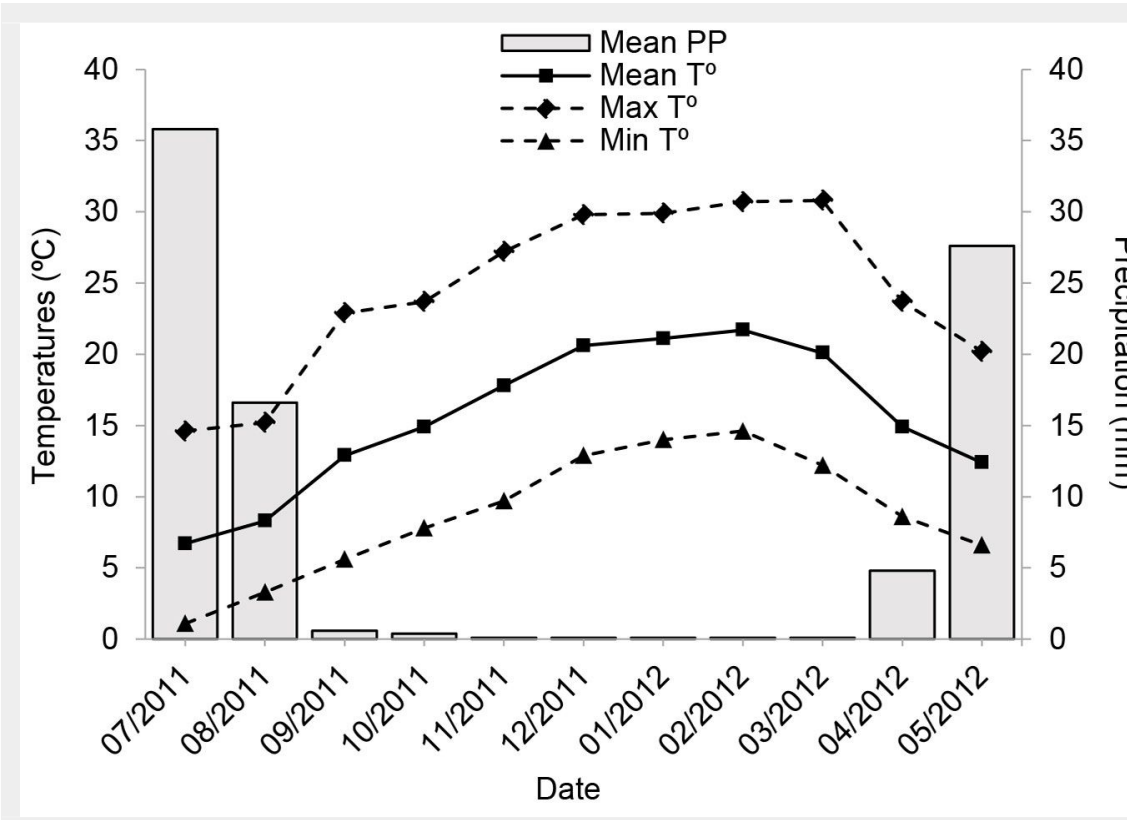

Fig. 1 - Monthly mean, minimum and maximum air temperature, and mean precipitation (PP - bars) in the field during the growing season 2011-2012 (Source: Estación Pudahuel, Dirección Meteorológica de Chile).

ity of atmospheric conditions among dates. After one growing season (May 2012), trees were dug up $(n=12)$ to evaluate the morphological variables of the shoot $\left(\mathrm{S}_{\mathrm{H}}\right.$, $S_{D}, S_{D M}$, and shoot:root ratio) and root systems (total $R_{L}$, total $R_{V}$, and $R_{D M}$ ). Plants were extracted using a hand shovel. Carefully, we dig a hole $1 \mathrm{~m}$ in depth with a radio of $1 \mathrm{~m}$ from the base of the tree. Roots were washed applying abundant water at low pressure on a fine mesh sieve to remove soil while retaining thin roots. Roots were grouped according to their diameter as fine $(<1 \mathrm{~mm})$, medium $(1-2$ $\mathrm{mm}$ ), and coarse $(>2 \mathrm{~mm}$ ) roots. Two new variables were evaluated: fine root volume (fine $\mathrm{R}_{\mathrm{V}}, \mathrm{cm}^{3}$ ) and specific root length $\left(\mathrm{S}_{\mathrm{RL}}\right)$. $S_{R L}$ was the quotient of total $R_{L}$ and $R_{D M}$. The remaining root morphological variables were measured following the same protocol as per the final nursery measurements.

\section{Statistical analysis}

For both nursery and field experiments, simple Pearson's correlations were used to examine the pairwise relationship between measured variables. Before testing, compliance with normality, homogeneity of variance, and linearity assumptions were verified for all variables. In the field experiment, variables that did not match the normality assumptions $\left(S_{H}, S_{D}\right.$, total $R_{L}$, total $R_{v}$, and $R_{D M}$ ) were logarithmically transformed (pre-transformation values are presented). Differences among variables evaluated in the nursery phase of the experiment were determined by a one-way analysis of variance test $(\alpha=0.05)$, and significant differences were identified by the Tukey's multiple comparison test ( $\alpha=$ 0.05). All data obtained in the field phase were subjected to a two-way ANOVA performed using a general linear model (GLM), to evaluate fertilization doses (F), watering regimes $(W)$, and fertilization dose $\times$ watering regime interaction $(\mathrm{F} \times \mathrm{W})$ effects $(a=0.05)$. When the $F \times W$ interaction was significant $(P<0.05, F$ test), we conducted the Tukey's multiple comparison test $(a=0.05)$. To analyze seedling survival, a chi-square test was applied based on the Kaplan-Meier method with a logrank test (Mantel-Cox). All statistical analyses were carried out using the SPSS ${ }^{\circledast}$ v 17.0 program (SPSS Inc., Chicago, IL, USA).

\section{Results}

\section{Nursery fertilization}

Fertilization treatment with the highest dose (12F) significantly affected all seedling morphological variables at the end of the nursery-growing period, with the exception of $S_{D}$ and foliar nutrient concentrations measured before field transplanting (Tab. 1). Seedlings grown at $12 \mathrm{~F}$ tended to have better shoot and root development compared with seedlings in the other treatment groups. The of seedlings had the lowest $\mathrm{S}_{D M}($ Tab. 1). There was a significant effect of $12 \mathrm{~F}$ on the slenderness $\left(\mathrm{S}_{\mathrm{I}}\right)$ seedlings compared with the oF. Foliar nutritional analysis showed higher foliar $\mathrm{N}$ for the $12 \mathrm{~F}$ seedlings in comparison to the oF and $3 \mathrm{~F}$. Foliar $\mathrm{P}$ concentrations were significantly higher in the $12 \mathrm{~F}$ seedlings in comparison to all other treatments. Foliar $\mathrm{K}$ concentration was higher in the of seedlings in comparison to all the other treatments (Tab. 1).

\section{Field survival}

Seedling field survival ranged from $80 \%$ to 
Tab. 1 - Morphological characteristics and foliar nutrient concentrations (N-P-K, $\left.\mathrm{g} \mathrm{kg}^{-1}\right)$ of Quillaja saponaria seedlings grown in nursery with different controlled-release fertilizer (CRF) doses $\left(0,3,6\right.$, and $12 \mathrm{~g} \mathrm{~L}^{-1}$ Basacote ${ }^{\circledast}$ Plus). Data recorded at the end of the nursery phase in June 2011 before planting. Means \pm SE $(n=15)$ with different letters indicate significant differences after Tukey's HSD test $(P<0.05)$.

\begin{tabular}{|c|c|c|c|c|c|c|}
\hline \multirow{2}{*}{ Variables } & \multicolumn{4}{|c|}{ Fertilization dose $\left(\mathrm{g} \mathrm{L}^{-1}\right)$} & \multirow{2}{*}{$F$ value } & \multirow{2}{*}{$P$ value } \\
\hline & 0 & 3 & 6 & 12 & & \\
\hline Shoot height $\left(\mathrm{S}_{\mathrm{H}}, \mathrm{cm}\right)$ & $18.88 \pm 0.39 \mathrm{~b}$ & $19.65 \pm 0.54 \mathrm{~b}$ & $20.31 \pm 0.22 b$ & $23.28 \pm 0.34 \mathrm{a}$ & 23.681 & $<0.001$ \\
\hline Stem diameter $\left(\mathrm{S}_{\mathrm{D}}, \mathrm{mm}\right)$ & $3.13 \pm 0.09$ & $2.95 \pm 0.05$ & $3.08 \pm 0.10$ & $3.45 \pm 0.09$ & 1.148 & 0.338 \\
\hline Shoot dry mass $\left(S_{D M}, g\right)$ & $1.21 \pm 0.03 c$ & $1.28 \pm 0.03 b$ & $1.38 \pm 0.04 \mathrm{~b}$ & $1.67 \pm 0.01 \mathrm{a}$ & 44.768 & $<0.001$ \\
\hline Slenderness $\left(\mathrm{S}_{\mathrm{I}}, \mathrm{cm} \mathrm{mm}^{-1}\right)$ & $6.10 \pm 0.21 b$ & $6.68 \pm 0.21 a b$ & $6.72 \pm 0.31 \mathrm{ab}$ & $6.82 \pm 0.21 \mathrm{a}$ & 3.858 & 0.014 \\
\hline Root dry mass $\left(R_{D M}, g\right)$ & $0.53 \pm 0.06 b$ & $0.56 \pm 0.03 b$ & $0.59 \pm 0.07 \mathrm{a}$ & $0.63 \pm 0.06 a$ & 14.908 & $<0.001$ \\
\hline Shoot/root ratio & $2.28 \pm 0.08 b$ & $2.29 \pm 0.07 b$ & $2.34 \pm 0.10 \mathrm{~b}$ & $2.65 \pm 0.04 a$ & 8.969 & $<0.001$ \\
\hline Foliar $\mathrm{N}\left(\mathrm{g} \mathrm{kg}^{-1}\right)$ & $22.40 \pm 1.30 \mathrm{~b}$ & $24.30 \pm 0.40 b$ & $25.50 \pm 0.70 \mathrm{ab}$ & $27.70 \pm 0.50 a$ & 7.917 & 0.004 \\
\hline Foliar $\mathrm{P}\left(\mathrm{g} \mathrm{kg}^{-1}\right)$ & $2.00 \pm 0.10 \mathrm{~b}$ & $2.00 \pm 0.00 \mathrm{~b}$ & $1.90 \pm 0.10 b$ & $2.30 \pm 0.10 \mathrm{a}$ & 5.619 & 0.012 \\
\hline Foliar $\mathrm{K}\left(\mathrm{g} \mathrm{kg}^{-1}\right)$ & $26.10 \pm 1.20 \mathrm{a}$ & $21.00 \pm 0.80 b$ & $19.50 \pm 0.30 b$ & $20.80 \pm 0.20 b$ & 15.028 & 0.001 \\
\hline
\end{tabular}

Tab. 2 - Two-way analysis of variance (ANOVA) results for treatment main effects for nursery fertilization effect (4 levels) and field watering regimes (2 levels) and their interaction for morphological and ecophysiological variables measured on Quillaja saponaria seedlings after outplanting. $\Psi_{\mathrm{w}}$ data were analyzed based on $\Psi_{\mathrm{w}}$ averages of the driest months (September, November, March, and April).

\begin{tabular}{|c|c|c|c|c|c|c|}
\hline \multirow{2}{*}{ Variables } & \multicolumn{2}{|c|}{ Fertilization dose $(\mathrm{F})$} & \multicolumn{2}{|c|}{ Watering regime $(\mathrm{W})$} & \multicolumn{2}{|c|}{ Interaction $\mathrm{F} \times \mathrm{W}$} \\
\hline & $F$ value & $P$ value & F value & $P$ value & F value & $P$ value \\
\hline Shoot height $\left(\mathrm{S}_{\mathrm{H}}, \mathrm{cm}\right)$ & 7.505 & $<0.001$ & 10.628 & 0.001 & 1.809 & 0.753 \\
\hline Stem diameter $\left(S_{D}, \mathrm{~mm}\right)$ & 6.841 & $<0.001$ & 153.327 & $<0.001$ & 35.852 & $<0.001$ \\
\hline Shoot dry mass $\left(S_{D M}, g\right)$ & 55.070 & $<0.001$ & 12.797 & 0.001 & 1.441 & 0.724 \\
\hline Total root length (total $R_{\mathrm{L}}, \mathrm{m}$ ) & 8.492 & $<0.001$ & 65.499 & $<0.001$ & 2.034 & 0.113 \\
\hline Total root volume (total $\mathrm{R}_{\mathrm{v}}, \mathrm{cm}^{3}$ ) & 44.973 & $<0.001$ & 628.780 & $<0.001$ & 15.148 & $<0.001$ \\
\hline Fine roots volume (fine $R_{v}, \mathrm{~cm}^{3}$ ) & 37.804 & $<0.001$ & 204.510 & $<0.001$ & 3.755 & 0.013 \\
\hline Specific root length $\left(\mathrm{S}_{\mathrm{RL}}, \mathrm{cm} \mathrm{g}^{-1}\right)$ & 22.507 & $<0.001$ & 58.911 & $<0.001$ & 3.072 & 0.031 \\
\hline Root dry mass $\left(\mathrm{R}_{\mathrm{DM}}, \mathrm{g}\right)$ & 4.088 & 0.009 & 222.983 & $<0.001$ & 14.753 & $<0.001$ \\
\hline Shoot/root ratio $\left(\mathrm{g} \mathrm{g}^{-1}\right)$ & 18.519 & $<0.001$ & 97.853 & $<0.001$ & 15.080 & $<0.001$ \\
\hline Pre-dawn xylem water potential $\left(\Psi_{\mathrm{w}}, \mathrm{MPa}\right)$ & 4.791 & 0.007 & 2.260 & 0.143 & 3.484 & 0.027 \\
\hline Maximal photochemical efficiency of PSII $\left(F_{v} / F_{m}\right)$ & 3.252 & 0.024 & 38.806 & $<0.001$ & 6.442 & $<0.001$ \\
\hline Stomatal conductance $\left(\mathrm{g}_{\mathrm{s}}, \mathrm{mmol} \mathrm{m}^{-2} \mathrm{~s}^{-1}\right)$ & 3.227 & 0.035 & 10.358 & 0.003 & 1.001 & 0.680 \\
\hline
\end{tabular}

$93 \%$ in all treatments. Previous nursery fertilization doses $\left(0,3,6\right.$, and $\left.12 \mathrm{~g} \mathrm{~L}^{-1}\right)$ and field watering regimes ( $\mathrm{W}+$ and $\mathrm{W}$-) had no effect on seedling field survival at the end of the study $\left(\chi^{2}=1.312, P<0.726\right)$.

\section{Shoot and root morphology}

There was a significant main effect of nursery fertilization and field watering regimes on $\mathrm{S}_{\mathrm{H}}, \mathrm{S}_{\mathrm{DM}}$, and total $\mathrm{R}_{\mathrm{L}}$ (Tab. 2). A significant interaction effect was also detected on $S_{D}$, total $R_{V}$, fine $R_{V}, S_{R L}, R_{D M}$, and the shoot:root ratio (Tab. 2).

Field seedling height $\left(\mathrm{S}_{\mathrm{H}}\right)$ was greater at $6 \mathrm{~F}$ seedlings regardless of watering regime
(Tab. 3). The oF seedlings with $\mathrm{W}+$ showed the highest $S_{D}$ value (Fig. 2A). $S_{D M}$ showed significant differences, for having the $12 \mathrm{~F}$ seedlings the greater values and the of seedlings the lowest (Tab. 3).

The shoot:root ratio under the $\mathrm{W}+$ treatment was significantly lower in of seedlings and $3 \mathrm{~F}$. Biomass allocation drastically changed when seedlings were transplanted from the nursery to the field, decreasing from a general average of 2.4 before (Tab. 1) to 0.5 after transplant (Fig. 2B). After the first dry season since outplanting, the lowest shoot:root ratio was observed in $\mathrm{OF}$ and $3 \mathrm{~F}$ seedlings (Fig. 2B).
The effect of CRF dose on root morphological variables was dependent on the level of soil water stress; water restriction (W-) resulted in a strong limitation of root growth. A significantly higher total $R_{\mathrm{L}}$ (Tab. 2) was found for the $6 \mathrm{~F}$ seedlings under $\mathrm{W}+(15.36 \pm 1.66 \mathrm{~m})$ compared with the of seedlings $(12.67 \pm 0.50 \mathrm{~m})$. For total $R_{v}$, the oF and the $12 \mathrm{~F}$ seedlings had significantly highest values. Similar results were observed under the $\mathrm{W}+$ treatment $(15.50 \pm$ $1.62 \mathrm{~cm}^{3}$ and $16.82 \pm 1.17 \mathrm{~cm}^{3}$, respectively). Fine $R_{V}$ represented approximately $50 \%$ of the total $R_{v}$, with a mean value of $6.32 \mathrm{~cm}^{3}$ for all treatments. For $6 \mathrm{~F}$ and $12 \mathrm{~F}$ seedlings

Tab. 3 - Results of aboveground growth of 2-year old Quillaja saponaria seedlings under four fertilization doses in the nursery and two field watering regimes (W+: $2 \mathrm{~L}_{\text {plant }}{ }^{-1} ; \mathrm{W}-$ : unwatered). Data obtained at the end of the dry season after outplanting (May 2012). Values are mean \pm SE $(n=12)$; means with different letters indicate significant differences after Tukey's HSD test $(P<0.05)$. (a): No interaction of fertilizer dose $\times$ watering regime.

\begin{tabular}{|c|c|c|c|c|c|c|}
\hline \multirow{2}{*}{ Variables } & \multicolumn{4}{|c|}{ Fertilization dose $(\mathrm{F})$} & \multicolumn{2}{|c|}{ Watering regime $(\mathrm{W})$} \\
\hline & $0 \mathrm{~g} \mathrm{~L}^{-1}$ & $3 \mathrm{~g} \mathrm{~L}^{-1}$ & $6 \mathrm{~g} \mathrm{~L}^{-1}$ & $12 \mathrm{~g} \mathrm{~L}^{-1}$ & $\mathrm{~W}+$ & W- \\
\hline Shoot height $\left(\mathrm{S}_{\mathrm{H}}, \mathrm{cm}\right)^{\mathrm{a}}$ & $36.06 \pm 1.61 \mathrm{~b}$ & $36.36 \pm 1.67 \mathrm{~b}$ & $41.46 \pm 1.04 \mathrm{a}$ & $36.21 \pm 0.98 b$ & $39.09 \pm 1.33 \mathrm{~A}$ & $35.96 \pm 1.31 \mathrm{~B}$ \\
\hline Shoot dry mass $\left(S_{D M}, g\right)^{a}$ & $4.96 \pm 0.22 c$ & $5.85 \pm 0.19 b$ & $5.62 \pm 0.21 b c$ & $7.29 \pm 0.12 a$ & $6.17 \pm 0.16 \mathrm{~A}$ & $5.69 \pm 0.21 \mathrm{~B}$ \\
\hline
\end{tabular}


with $W_{+}$, fine $R_{v}$ was significantly greater $\left(8.61 \pm 0.24 \mathrm{~cm}^{3}\right.$ and $8.45 \pm 0.16 \mathrm{~cm}^{3}$, respectively) than for the other treatments (Tab. 2). The highest values of $S_{R L}$ were found for the $3 \mathrm{~F}$ and $6 \mathrm{~F}$ seedlings, both under W- (Fig. 2C). The W- condition improved the $\mathrm{S}_{\mathrm{RL}}$ by more than $30 \%$ as compared with the $\mathrm{W}+$ condition. $\mathrm{R}_{\mathrm{DM}}$ had maximum values at the oF and $3 \mathrm{~F}$ seedlings, both under W+ (Fig. 2D).

\section{Xylem water potential, chlorophyll fluorescence, and stomatal conductance}

There was a significant effect of nursery fertilization and post-planting watering treatments on $g_{s}$ (Tab. 2), and a significant interaction effect on pre-dawn $\Psi_{w}$ and $\mathrm{F}_{\mathrm{v}} / \mathrm{F}_{\mathrm{m}}$ (Tab. 2). A large drop in pre-dawn $\Psi_{\mathrm{w}}$ was observed in all nursery fertilization and post-planting watering treatments during the dry period, with minimum values fluctuating from -4.43 to $-5.60 \mathrm{MPa}$ at the end of the season, but with no significant differences among treatments (Fig. 3). The combination of no fertilizer and $\mathrm{W}_{+}$had significantly higher pre-dawn $\Psi_{w}$ values during September $(-2.25 \pm 0.24 \mathrm{MPa})$ and November $(-2.82 \pm 0.16 \mathrm{Mpa}-$ Fig. 3$)$. The of seedlings had the highest average values of pre-dawn $\Psi_{w}(-3.09 \pm 0.23 \mathrm{MPa})$ during the driest months compared with the other treatments. Once the wet season started (second week of May 2012 - Fig. 1), the water status of all seedlings recovered quickly, with values of pre-dawn $\Psi_{w}$ ranging from -1.05 to $-1.50 \mathrm{MPa}$ for that sampling date (Fig. 3), but with no differences among treatments. For midday $F_{v} / F_{m}$, the impact of $W$ - was significant for the three fertilization doses (Fig. 4). The W+ seedlings showed significantly higher values of $F_{\mathrm{v}} / F_{\mathrm{m}}$ compared with the $\mathrm{W}$ - seedlings. Seedlings of oF, independent of the watering regime, had significantly higher values of $F_{v} / F_{m}$ at the end of the dry season (April 2012) compared with seedlings in the fertilization treatments. For $g_{s}$ at the end of the dry season (April 2012), there were significant main effects of nursery fertilization and watering regimes (Tab. 2).

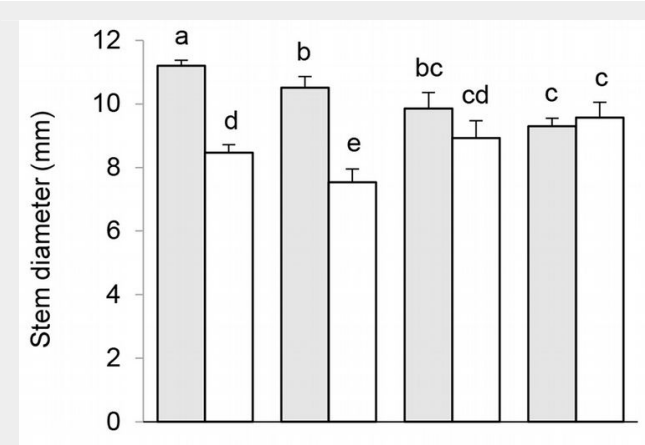

(A)

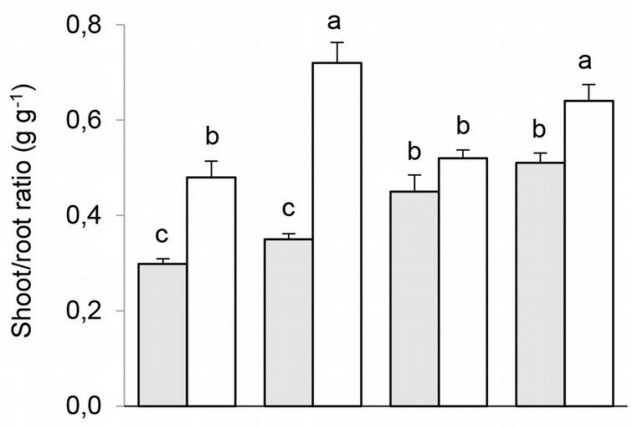

(B)
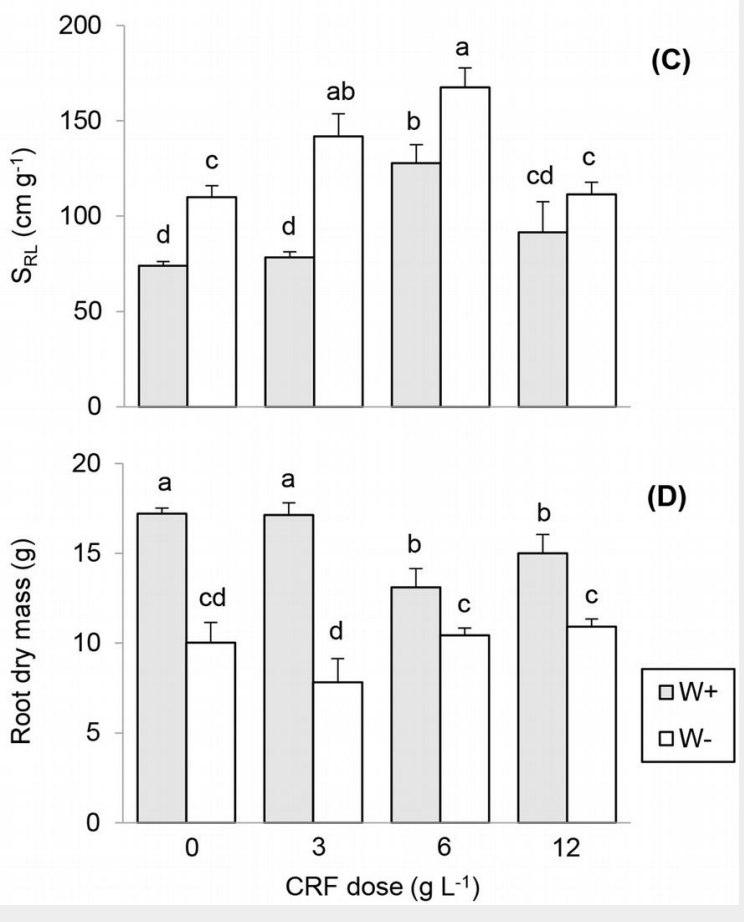

Fig. 3 - Mean pre-dawn xylem water potential $\left(\Psi_{w}\right)$ of Quillaja saponaria seedlings grown under four nursery controlled-release fertilizer (CRF) doses and two field watering regimes imposed after outplanting: watered $2 \mathrm{~L} \mathrm{plant}^{-1}(\mathrm{~W}+$, solid line) and not watered (W-, dashed line). Mean values $\pm \operatorname{SE}(n=$ 5 ); bars with asterisks indicate significant differences ( $P<0.05$, Tukey's HSD test) in measurements in September and November 2011, indicating greater drought resistance because of a smaller seedling size in relation to the other fertilization treatments.

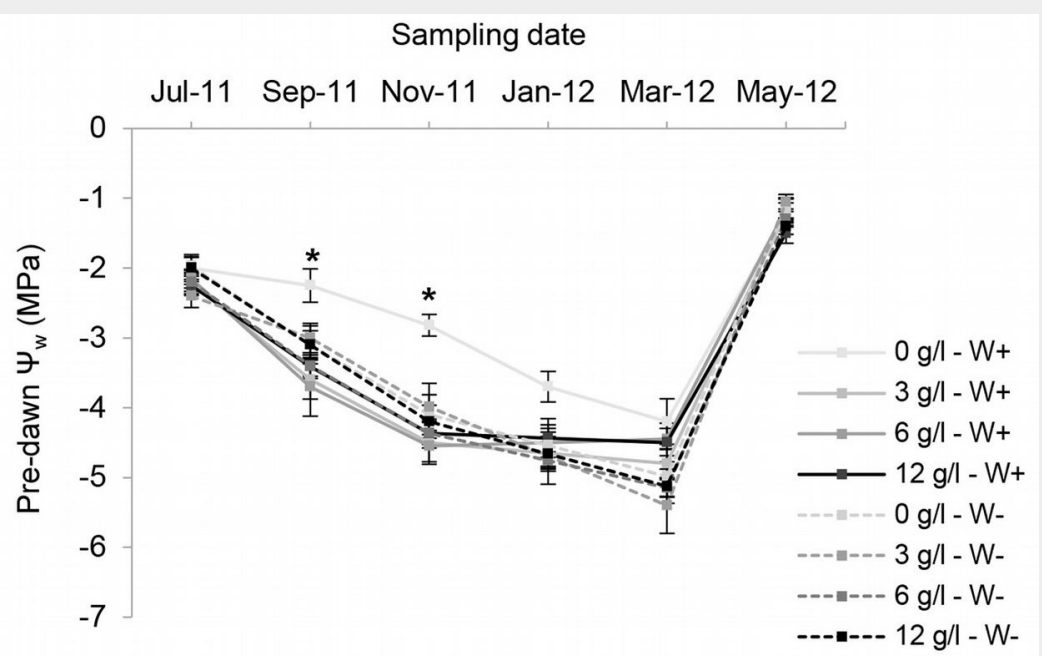

Fig. 2 - Mean stem diameter (A), shoot/root ratio (B), specific root length (C) and root dry mass (D) of Quillaja saponaria seedlings grown under four nursery controlled-release fertilizer (CRF) doses two field watering regimes imposed after outplanting: watered $2 \mathrm{~L}_{\text {plant }}^{-1}(\mathrm{~W}+$, gray bars $)$ and no watered (W-, white bars). The evaluation was made at the end of the first drought season after outplanting (May 2012). Mean values $\pm \operatorname{SE}(n=12)$ are reported. Different letters indicate significant differences after Tukey's HSD test $(P<0.05)$. 


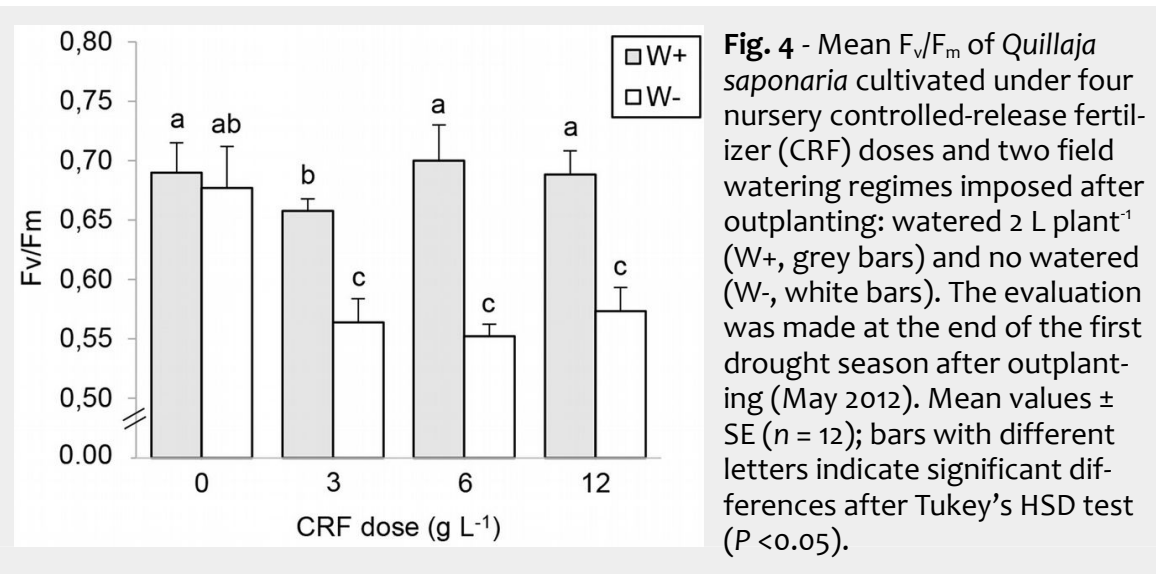

\section{Discussion}

Morphological responses of seedlings

Nutrient loading at the nursery affected the morphological traits of seedlings under different watering regimes after the first growing season in the field. However, these differences did not condition seed ling survival. Under the high dose treatment $(12 \mathrm{~F})$ applied in the nursery, there was an improvement in shoot productivity after outplanting, but this did not represent a significant contribution to the devel opment of drought-avoidance traits in Q. saponaria when no water was applied for 7 months. The survival of this group of seedlings was higher compared with other re forestation studies that reported early severe mortality for this species (Holmgren et al. 2000, Becerra et al. 2011). However, none of these previous studies considered early water application or nursery fertilization, or completely controlled herbivory.

The drastic changes in shoot:root ratio experienced by $Q$. saponaria in the transition from the nursery to the field indicated its ability to partition biomass to optimize its water balance. Different studies have suggested that reforestation success in Mediterranean systems is affected by the ability of tree seedlings to partition their above- and belowground biomass in a way that optimizes their water balance (Lloret et al. 1999, Ovalle et al. 2015). In fact, in the current study, an adequate biomass balance for severe drought conditions might have been achieved without any influence of fertilization. Similar responses were also reported for Mediterranean species when they were fertilized with low doses of CRF (Osmocote $^{\circledast}, \quad \mathrm{N}: \mathrm{P}: \mathrm{K}$ 14:8:14) under controlled conditions (Hernández et al. 2009).

Higher doses of CRF (12F) resulted in the greatest $R_{D M}$ on seedlings grown in the nursery. However, this positive response was not maintained after outplanting and contrasted with other recent studies conducted in Mediterranean conditions that suggested that a high nutrient supply generates early root growth and a positive carbon balance that helps sustain the demand for resources to maintain growth biomass (Luis et al. 2009, Cuesta et al. 2010, VillarSalvador et al. 2012). The low $R_{D M}$ could be attributed to the effects of residual nutrients from the fertilizer contained within the polymer-coated fertilizer, and the root plug, which tends to inhibit the growth ability of roots in the planting hole under low soil water available (Idris et al. 2004, Jacobs et al. 2004). By contrast, in more temperate and wet environments, CRF promoted root development (Timmer \& Teng 2004, Haase et al. 2006). The latter was corroborated by the control (OF) and low dose $(3 \mathrm{~F})$ treatments, both with $\mathrm{W}_{+}$, which had higher growth in $\mathrm{R}_{\mathrm{DM}}$ after outplanting.

In our study, the highest $S_{R L}$ values were found in the $\mathrm{W}$ - treatment, suggesting that Q. saponaria has the ability to alter the morphological components of its root system under drought conditions. This response was maximized in the low $(3 \mathrm{~F})$ and medium dose (6F) treatments applied in the nursery. Other studies carried out in the Iberian Peninsula with Mediterranean species grown under low soil nutrient status also found an increment in $\mathrm{S}_{\mathrm{RL}}$ (Trubat et al. 2012). We had hypothesized that the effect of high seedling nutritional status on root growth would be reflected by an improvement of the ability to maintain high water potential. However, in our study, the greatest ability to maintain high $\Psi_{w}$ during the first months (September to November 2011) of the dry season was only significant for the control (OF) treatment with watering $(\mathrm{W}+)$. This greater drought resistance might have been associated with the higher stem diameter, higher root dry mass, and lower shoot:root ratio of these seedlings compared with those subject to other treatments. It has been suggested that this phenotype is favored in environments with severe summer drought (Hernández et al. 2009, Cortina et al. 2013). Our findings differed to those of other studies that reported a positive relation between nutrient availability and drought resistance (Cuesta et al. 2010, Villar-Salvador et al. 2012), with the exception of $S_{D M}$, which had high values in the high dose treatment (12F) attributed to high leaf $\mathrm{N}$ and $\mathrm{P}$ nutrient load at the end of the drought period. However, there was no response in root biomass, which did not match what expected. Under mild Mediterranean summer droughts, there is a positive effect of larger seedling size with high $\mathrm{N}$ concentration on water status and post-planting survival (Luis et al. 2009, Oliet et al. 2009). Differences in the results of these and the current study could be due to the length of the drought period (7 months) that occurred during this study, which was more severe than in other studies conducted in the Iberian Mediterranean region.

\section{Seedling ecophysiological performance} after outplanting

Following 7 months of drought, the control (oF) treatment with no water (W-) had the highest $F_{v} / F_{m}$, compared with the fertilized treatments. The latter suffered a drastic decrease in $F_{v} / F_{m}$ values under water stress (W-), supporting the idea that small seedling phenotypes might exhibit a better resistance to an extended drought. These effects are further accentuated in semiarid Mediterranean environments, given the high light intensity and temperatures reaching the leaf surface (Flexas et al. 2014). Vilagrosa et al. (2003) reported an exponential decrease of $F_{v} / F_{m}$, to values close to 0.20 in an experiment conducted in a Mediterranean zone of eastern Spain, where Quercus coccifera seedlings were preconditioned to drought. Our study showed $F_{v} / F_{m}$ values greater than 0.55 in all treatments, illustrating the high photochemical efficiency of $Q$. saponaria under conditions of low water availability.

The water status of seedlings was strongly altered by summer drought. It is likely that the intensity of water stress at this stage could overwhelm the fertilization effects on $\Psi_{w}$. However, following the start of the wet season (May 2012), seedlings rapidly recovered their plant water status, reaching higher $\Psi_{w}$ values than before the onset of drought. A similar response in water potential was experienced by Quercus rubra seedlings as the water supply recovered (Jacobs et al. 2009). In addition, these authors also reported an increase in photosynthetic activity and stomatal conductance, which could indicate an adaptive response to drought. One of the key adaptive morphological characteristics that could explain the high resistance is the deep rooting habit of Q. saponaria. Giliberto \& Estay (1978) found a correlation between water status and $\Psi_{w}$ during summer drought for Q. saponaria, contrasting to other South American Mediterranean species. This ability to control the water balance could be influenced by the ability of Q. saponaria to rapidly modify its biomass allocation of shoots and roots during the growing season (Donoso et al. 2011). However, these studies were conducted in sites that were highly degraded, and more exposed to herbivores (Morales et al. 2015).

\section{Conclusions}

Our results suggest that high fertilization doses produced larger seedlings in the nursery, with high $\mathrm{N}$ and $\mathrm{P}$ foliar concentra- 
tions, which resulted in increased shoot dry mass after outplanting. However, unfertilized seedlings developed better droughtavoidance traits after outplanting, such as higher stem diameter, higher root dry mass, and lower shoot:root ratio, but these were associate with high water availability. Drought-avoidance traits influenced the ability to maintain higher xylem water potential during the first months of drought and chlorophyll fluorescence at the end of summer season. Therefore, our study demonstrated that higher fertilizer doses applied in nursery, although improving shoot productivity after outplanting, do not represent a significant contribution to the development of drought-avoidance traits in Q. saponaria under drought conditions. For dryland reforestation, a relevant nursery decision is the downward adjustment of fertilization doses to obtain seedlings better conditioning to anticipate field moisture stress.

\section{Acknowledgements}

This work was supported by CONICYT $\mathrm{N}^{\circ}$ 24121675-2012, MECESUP-UC0707, and Minera AngloAmerican Chile. The authors would like to thank Vivero y Jardín Pumahuida Ltda for providing seedlings and Germán Greve from the Universidad de Chile. We thank the Marie Curie Actions fellowships ( $7^{\text {th }}$ European Community Framework Programme), ForEAdapt 269257, and the Center of Applied Ecology \& Sustainability (CAPES) by CONICYT FB-0002-2014. We thank Julio Calderón, Mónica Escobar, and Rommy Oliva who provided technical support in the field and laboratory work. We are thankful to James Burger for his collaboration and constructive comments.

\section{References}

Becerra PI, González-Rodríguez V, Smith-Ramírez C, Armesto JJ (2011). Spatio-temporal variation in the effect of herbaceous layer on woody seedling survival in a Chilean Mediterranean ecosystem. Journal of Vegetation Science 22: 847-855. - doi: 10.1111/j.1654-1103.2011. 01291.X

Becerra PI, Cruz G, Ríos S, Castelli G (2013). Importance of irrigation and plant size in the establishment success of different native species in a degraded ecosystem of central Chile. Bosque 34: 23-24. - doi: 10.4067/S0717-920020 13000100012

Benigno S, Dixon K, Stevens J (2014). Seedling mortality during biphasic drought in sandy Mediterranean soils. Functional Plant Biology 41: 1239-1248.

Cortina J, Vilagrosa A, Trubat R (2013). The role of nutrients for improving seedling quality in drylands. New Forests 44: 719-732. - doi: 10.1007 /s11056-013-9379-3

Cuesta B, Villar-Salvador P, Puértolas J, Jacobs D, Rey-Benayas JM (2010). Why do large, nitrogen rich seedlings better resist stressful transplanting conditions? A physiological analysis in two functionally contrasting Mediterranean forest species. Forest Ecology and Management 260: 71-78. - doi: 10.1016/j.foreco.2010.04.002
Donoso C (1982). Reseña ecológica de los bosques Mediterráneos de Chile [Ecological description of Chilean Mediterranean forest]. Bosque 4: 117-146.

Donoso S, Peña K, Pacheco C, Luna G, Aguirre A (2011). Physiological and growth response in Quillaja saponaria and Cryptocarya alba plants under restricted water conditions. Bosque 32: 187-195. - doi: 10.4067/S0717-920020110002000 09

Flexas J, Diaz-Espejo A, Gago J, Gallé A, Galmés J, Gulías J, Medrano H (2014). Photosynthetic limitations in Mediterranean plants: a review. Environmental and Experimental Botany 103: 12-23. - doi: 10.1016/j.envexpbot.2013.09.002

Giliberto J, Estay H (1978). Seasonal water stress in some chilean matorral shrubs. Botanical Gazette 139 (2): 236-240. - doi: 10.1086/336995

González M, Quiroz I, García E, Soto H (2011). Estándares de producción de plantas de Quillay (Quillaja saponaria Mol.) [Production standards for Quillay (Quillaja saponaria Mol.) seedlings]. Revista Chile Forestal 353: 43-46.

Haase DL, Rose R, Trobaugh J (2006). Field performance of three stock sizes of Douglas-fir container seedlings grown with slow-release fertilizer in the nursery growing medium. New Forests 31: 1-24. - doi: 10.1007/s1105600453966 Hernández E, Vilagrosa A, Luis VC, Llorca $M$, Chirino E, Vallejo VR (2009). Root hydraulic conductance, gas exchange and leaf water potential in seedlings of Pistacia lentiscus L. and Quercus suber $L$. grown under different fertilization and light regimes. Environmetal and Experimental Botany 67: 269-276. - doi: 10.1016/j.env expbot.2009.07.004

Holmgren M, Segura A, Fuentes E (2000). Limiting mechanisms in the regeneration of the chilean matorral experiments on seedling establishment in burned and cleared mesic sites. Plant Ecology 147: 49-57. - doi: 10.1023/A:1009 804726307

Idris M, Salifu KF, Timmer VR (2004). Root plug effects on early growth and nutrition of container black spruce seedlings. Forest Ecology and Management 195: 399-408. - doi: 10.1016/j. foreco.2004.03.005

Jacobs DF, Rose R, Haase D, Alzugaraya P (2004). Fertilization at planting impairs root system development and drought avoidance of Douglas-fir (Pseudotsuga menziesii) seedlings. Annals of Forest Science 61: 643-651. - doi: 10.1051/forest:2004065

Jacobs DF, Salifu KF, Davis AS (2009). Drought susceptibility and recovery of transplanted Quercus rubra seedlings in relation to root system morphology. Annals of Forest Science 66: 1-12. - doi: 10.1051/forest/2009029

Leiva MJ, Fernández-Alés R (1998). Variability in seedling water status during drought within a Quercus ilex subsp. ballota population, and its relation to seedling morphology. Forest Ecology and Management 111: 147-156. - doi: 10.1016/ S0378-1127(98)00320-X

Lloret F, Casanovas C, Peñuelas J (1999). Seedling survival of Mediterranean shrubland species in relation to root:shoot ratio, seed size and water and nitrogen use. Functional Ecology 13: 210-216. - doi: 10.1046/j.1365-2435.1999. 00309.x

Lo Gullo MA, Salleo S (1988). Different strategies of drought resistance in three Mediterranean sclerophyllous trees growing in the same environmental conditions. New Phytologist 108: 267-276. - doi: 10.1111/j.1469-8137.1988.tbo4162.x Luis VC, Puértolas J, Climent J, Peters J, González-Rodríguez AM, Morales $D$, Jiménez MS (2009). Nursery fertilization enhances survival and physiological status in Canary Island pine (Pinus canariensis) seedlings planted in a semiarid environment. European Journal of Forest Research 128: 221-229. - doi: 10.1007/s10342-0090257-7

Luna G (2006). Evaluación de parámetros fisiológicos y de crecimiento en plantas de Quillaja saponaria Mol. bajo condiciones de déficit hídrico [Evaluation of physiological parameters and growth in Quillaja saponaria Mol. plants under water deficit]. MSc thesis, Universidad de Chile, Santiago, Chile, pp. 145.

Maxwell K, Johnson GN (2000). Chlorophyll fluorescence-a practical guide. Journal of Experimental Botany 51: 659-68. - doi: 10.1093/jexbot/ 51.345.659

Morales N, Becerra P, Arellano E, Gilabert H (2015). Effect of large and small herbivores on seed and seedling survival of Beilschmiedia miersii in central Chile. Bosque 36 (1): 127-132. doi: 10.4067/S0717-92002015000100014

Oliet J, Planelles R, Artero F, Valverde R, Jacobs $D$, Segura M (2009). Field performance of Pinus halepensis planted in Mediterranean arid conditions: relative influence of seedling morphology and mineral nutrition. New Forests 37: 313331. - doi: 10.1007/s11056-008-9126-3

Olsen SR, Sommers LE (1982). Phosphorous. In: "Methods of soil analysis, Part 2" (Page AL, Miller RH, Keeney DR eds). SSSA-ASA, Madison, Wisconsin, USA, pp. 403-430.

Ovalle JF, Arellano EC, Ginocchio R (2015). Tradeoffs between drought survival and rooting strategy of two South American Mediterranean tree species: implications for dryland forests restoration. Forests 6: 3733-3747. - doi: 10.3390/ f6103733

Padilla F, Miranda J, Armas C, Pugnaire F (2015). Effects of changes in rainfall amount and pattern on root dynamics in an arid shrubland. Journal of Arid Environments 114: 49-53. - doi: 10.1016/j.jaridenv.2014.11.005

Pardos M, Calama R, Mayoral C, Madrigal G, Sánchez-González M (2014). Addressing post-transplant summer water stress in Pinus pinea and Quercus ilex seedlings. iForest 8: 348-358. - doi: 10.3832/ifor1256-007

Peñuelas J (2001). Severe drought effects on Mediterranean woody. Forest Science 47: 214218. [online] URL: http://www.ingentaconnect. com/content/saf/fs/2001/00000047/00000002/a rtoo010

Sparks DL (1996). Method of soil analysis, Part 3. SSSA-ASA, Madison, Wisconsin, USA. pp. 1184. Tan W, Hogan GD (1997). Physiological and morphological responses to nitrogen limitation in jack pine seedlings: potential implications for drought tolerance. New Forests 14: 19-31. - doi: 10.1023/A:1006546014858

Timmer VR, Teng Y (2004). Pretransplant fertilization of containerized Picea mariana seedlings: calibration and bioassay growth response. Canadian Journal of Forest Research 34: 2089-2098. - doi: 10.1139/x04-088 
Trubat R, Cortina J, Vilagrosa A (2006). Plant morphology and root hydraulics are altered by nutrient deficiency in Pistacia lentiscus (L.). Trees 20: 334-339. - doi: 10.1007/s00468-0050045-z

Trubat R, Cortina J, Vilagrosa A (2008). Shortterm nitrogen deprivation increases field performance in nursery seedlings of Mediterranean woody species. Journal of Arid Environments 72: 879-890. - doi: 10.1016/j.jaridenv.20 07.11 .005

Trubat R, Cortina J, Vilagrosa A (2012). Root architecture and hydraulic conductance in nutrient deprived Pistacia lentiscus L. seedlings. Oecologia 170:899-908. - doi: 10.1007/s00442012-2380-2
Valenzuela L (2007). Evaluación de un ensayo de riego y fertilización de Quillay (Quillaja saponaria Mol.) en la Región Metropolitana de Chile [Evaluation of irrigation and fertilization trials in Quillaja saponaria Mol. in the Metropolitan region of Chile]. MSc thesis, Universidad de Chile, Santiago, Chile, pp. 155.

Valladares F, Sánchez-Gómez D (2006). Ecophysiological traits associated with drought in Mediterranean tree seedlings: individual responses versus interspecific trends in eleven species. Plant Biology 8: 688-97. - doi: 10.1055/s2006-924107

Vallejo VR, Smanis A, Chirino E, Fuentes D, Valdecantos A, Vilagrosa A (2012). Perspectives in dryland restoration: approaches for climate change adaptation. New Forests 43: 561-579. doi: 10.1007/s11056-012-9325-9

Vilagrosa A, Cortina J, Gil-Pelegrin E, Bellot J (2003). Suitability of drought-preconditioning techniques in Mediterranean climate. Restoration Ecology 11: 208-216. - doi: 10.1046/j.1526100X.2003.00172.x

Villar-Salvador P, Puértolas J, Cuesta B, Peñuelas J, Uscola M, Heredia-Guerrero N, Rey-Benayas JM (2012). Increase in size and nitrogen concentration enhances seedling survival in Mediterranean plantations. Insights from an ecophysiological conceptual model of plant survival. New Forests 43: 755-770. - doi: 10.1007/s11056-0129328-6 